\title{
Prevalence and etiological agents for chronic suppurative otitis media in a tertiary hospital in Tanzania
}

\author{
Zephania Saitabau Abraham", Daudi Ntunaguzi ${ }^{2}$, Aveline Aloyce Kahinga ${ }^{2}$, Kassim Babu Mapondella²,
} Enica Richard Massawe ${ }^{2}$ Emmanuel James Nkuwi ${ }^{3}$ and Aslam Nkya ${ }^{2}$

\begin{abstract}
Objective: Chronic suppurative otitis media is among the most common otological condition reported in otorhinolaryngology practice commonly attributing to preventable hearing loss. The aim of this study was to determine the prevalence and etiological agents for chronic suppurative otitis media in our department.

Results: A total of 5591 patients were recruited in this study and only 79 (1.4\%) had chronic suppurative otitis media. A male preponderance 43 (54.4\%) was noted in this study and the left ear (58.2\%) was more commonly affected compared to the right ear. Central perforation was the commonest pattern of presentation and was reported in $53 \%$ of cases though none had attic perforation. Of the 81 processed ear swabs, microbial growth was seen in majority 80 (98.8\%) whilst one sample showed no microbial growth whereas 52.5\% had polymicrobial growth. Among the isolates, most were gram negative species accounting for $59.7 \%$ while gram positive bacteria accounted for $25.6 \%$ and fungi accounted for $14.7 \%$. Most of these isolates were facultative anaerobes. Klebsiella pneumoniae (20.2\%) was the commonest isolates while Escherichia coli and Pseudomonas aeruginosa were equally least isolated (10.9\%). Tested isolates were most sensitive to Ciprofloxacin, Gentamycin, Ceftriaxone and Amikacin and least sensitive to Amoxicillin/ clavulanic acid and Ampicillin.
\end{abstract}

Keywords: Prevalence, Aetiology, Chronic suppurative otitis media, Muhimbili, Tanzania

\section{Introduction}

Chronic suppurative otitis media (CSOM) is a disease condition associated with chronic inflammation of the middle ear cleft characterized by persistent perforation of the tympanic membrane with recurrent or persistent mucopurulent otorrhoea. The duration of otorrhoea for classifying CSOM has been the subject of discussion among Otorhinolaryngologists with duration ranging from between 3 weeks to 3 months. In this study the period taken will be at least 2 weeks in accordance with World Health Organization recommendation [1].

It is also one of the leading causes of preventable hearing loss worldwide and in most cases it is a sequela of

\footnotetext{
*Correspondence: zsaitabau@yahoo.com

${ }^{1}$ Department of Surgery, University of Dodoma, College of Health and Allied Sciences, Box 259, Dodoma, Tanzania
}

Full list of author information is available at the end of the article improperly attended acute otitis media and it consequently impairs one's quality of life $[1,2]$.

Hearing loss is common among patients with CSOM and exceeds $30 \mathrm{~dB}$ and with a tendency to occur in about 50 to $60 \%$ of such patients $[3,4]$. Conductive hearing loss is typically moderate to severe in up to two-thirds of patients and being marked at low frequencies and with increased bone conduction threshold tendency [4-12].

The site of the perforation corresponds to degree of hearing loss, with posterior perforations having greater decibel level loss probably as a result of loss of protection of the round window membrane from impinging sound pressure waves [7].

Methicillin resistant Staphylococcus aureus (MRSA) and methicillin-susceptible Staphylococcus aureus (MSSA) have been found in pus swab cultures of patients with CSOM and this poses a significant challenge in its 
medical management due to its resistance to commonly used antibiotics $[13,14]$.

On the other hand, there has been increased incidence of multi drug resistance which is another hindrance as they are related to increased complications associated with CSOM [13, 14]. In Tanzania, most of the available studies were based on the prevalence of this condition and very few studies have been conducted to look on the bacteriological and sensitivity pattern to antibiotics which is pertinent in the management of such patients.

\section{Main text \\ Methods \\ Study design, participants and sampling method}

This was a hospital based descriptive cross-sectional study conducted between September 2015 and February 2016 and included 1200 patients who attended Otorhinolaryngology (ORL) Department at Muhimbili National Hospital. Convenient sampling technique was utilized.

\section{Inclusion and exclusion criteria}

All adult patients who consented to participate in the study and those under the age of 18 years whose parents/ caretakers consented on their behalf. Patients on regular follow up were excluded.

\section{Specimen collection procedures}

Pus swab was collected from the external auditory canal and introduced into Amies transport medium bottle and sent for laboratory analysis.

\section{Laboratory procedures}

From each specimen, a portion was subjected to primary gram stain for pus cells and possible organism while the remaining portions were inoculated into Blood agar (Oxoid, UK), and MacConkey agar (Oxoid, UK) and incubated aerobically at $37^{\circ} \mathrm{C}$ for $24-48 \mathrm{~h}$.

\section{Identification of bacterial pathogens}

Identification of pathogens was based on Microscopy (Gram stain, shape, cells arrangement) and colony characteristics (colony morphology, hemolysis on blood agar, changes in the physical appearance of the differential media). Organisms from discrete colonies were cultured into Nutrient Agar (Oxoid, UK) for subsequent. Biochemical tests. Gram positive isolates were tested for catalase and Coagulase tests while biochemical tests for gram negative isolated bacteria were tested for oxidase, Triple sugar Iron (TSI), Sulphur indole and motility (SIM), urease production and citrate utilization [15].

\section{Antimicrobial susceptibility testing}

Antibiotic susceptibility pattern of isolated bacteria pathogens was performed using modified Kirby Bauer disc diffusion method according to the guidelines of the clinical and Laboratory Standard Institute (CLSI) [16].

A colony suspension with concentration equivalent to 0.5 McFarland solution was prepared for each identified isolate and inoculated into Mueller-Hinton-Agar (Oxoid, UK). Appropriate Selected Antibiotic discs were placed onto the media and incubated at $37^{\circ} \mathrm{C}$ for $24 \mathrm{~h}$.

Gram positive isolates were tested against Ampicillin $(10 \mu \mathrm{g})$, Amoxicillin/clavulanate $(20 / 10 \mu \mathrm{g})$, Ceftriaxone $(30 \mu \mathrm{g})$, Gentamycin $(10 \mu \mathrm{g})$, Ciprofloxacin $(5 \mu \mathrm{g})$, Trimethoprim/sulfamethoxazole $(1.25 / 23.75 \mu \mathrm{g})$, Chloramphenicol $(30 \mu \mathrm{g})$, Amikacin $(17 \mu \mathrm{g})$ and Cephalexin $(18 \mu \mathrm{g})$.

Gram negative organisms were tested against Ampicillin $(10 \mu \mathrm{g})$, Amoxicillin/clavulanate $(20 / 10 \mu \mathrm{g})$, Ceftriaxone $(30 \mu \mathrm{g})$, Gentamicin $(10 \mu \mathrm{g})$, Ciprofloxacin $(5 \mu \mathrm{g})$, Triomethoprim/sulfamethoxazole $(1.25 / 23.75 \mu \mathrm{g})$ and Chloramphenicol $(30 \mu \mathrm{g})$. Reference stains used for quality control were Staphylococcus aureus (American Type Culture Collection; ATCC 25922 and ATCC 29213), Escherichia coli (ATCC 25922), Pseudomonas aeruginosa (ATCC2785) $[15,16]$.

\section{Data analysis}

Data analysis was done using the Statistical Package for Social Sciences version 21. P-value of $<0.05$ was considered statistically significant.

\section{Results}

Demographic characteristics of study participants

A total of 5591 patients were recruited and include both in and out patients. The age distribution ranged from 7 months to 82 years. The mean age (Standard Deviation; SD) of study participants was 12.9 ( $\mathrm{SD} \pm 7.9)$. Majority of patients were over 40 years old $(28.1 \%)$ and the minority (4.9\%) were between 16 and 20 years of age. Slight female predominance $(52.4 \%)$ was noted in this study (Table 1).

\section{Prevalence of chronic suppurative otitis media}

Table 2 shows the prevalence of CSOM with regard to age and gender. Of the 5591 patients, 79 (1.4\%) had CSOM. The proportion of CSOM was highest in patients aged between 11 and 15 years (3\%) and least in those aged above 40 years $(0.6 \%)$. A male predominance of $54.4 \%$ was also noted. 
Table 1 Demographic characteristics of the eligible patients

\begin{tabular}{lcl}
\hline Variable & Frequency & Percentage \\
\hline Age group (years) & & \\
$<5$ & 1468 & 26.3 \\
$6-10$ & 416 & 7.4 \\
$11-15$ & 332 & 5.9 \\
$16-20$ & 274 & 4.9 \\
$21-25$ & 445 & 8.0 \\
$25-30$ & 391 & 7.0 \\
$31-35$ & 348 & 6.8 \\
$36-40$ & 342 & 6.1 \\
$>40$ & 1575 & 28.1 \\
Sex & & \\
Male & 2663 & 47.6 \\
Female & 2958 & 52.4 \\
Total & 5591 & 100 \\
\hline
\end{tabular}

Table 2 Prevalence of chronic suppurative otitis media by age and sex

\begin{tabular}{lccl}
\hline Variables & Frequency & CSOM & Proportion (\%) \\
\hline Age group (years) & & & \\
$<5$ & 1468 & 21 & 1.4 \\
$6-10$ & 416 & 9 & 2.2 \\
$11-15$ & 332 & 10 & 3.0 \\
$16-20$ & 274 & 7 & 2.6 \\
$21-25$ & 445 & 8 & 1.8 \\
$26-30$ & 391 & 4 & 1.0 \\
$31-35$ & 348 & 8 & 2.3 \\
$36-40$ & 342 & 3 & 0.9 \\
$>40$ & 1575 & 9 & 0.6 \\
Sex & & & \\
Male & 2663 & 43 & 1.6 \\
Female & 2958 & 36 & 1.2 \\
Total & 5591 & 79 & 1.4 \\
\hline
\end{tabular}

Lateralization and types of tympanic membrane perforation Unilateral involvement (97.5\%) was commoner than bilaterality (2.5\%). Left ear infection and bilaterality accounted for $58.3 \%$ and $2.5 \%$ of cases respectively. Central perforation (53.2\%) was the predominant type.

\section{Distribution of bacterial and fungal isolates}

Figure 1 depicts distribution of bacterial and fungal isolates. Of the 79 patients with CSOM in whom a pus specimen was collected for culture, $98.8 \%$ yielded a positive culture. Most of culture growth yielded polymicrobial growth $(52.5 \%)$, in which the most common pathogen was a mixture of Proteus mirabilis and Klebsiella pneumoniae (16.7\%) (Fig. 1). As for single microbial growth, Escherichia coli and Staphylococcus aureus were equally prevalent (21.1\%).

Overall, Gram negative bacteria were more common (59.7\%) and least was fungi (Candida albicans) (14.7\%) (Additional file 1: Figure S1). Among Gram-negative bacteria, Klebsiella pneumoniae was the most prevalent (33.8\%), Among Gram-positive bacteria, Coagulase negative Staphylococcus spp. was the commonest (54.5\%). Generally, of all isolates, Klebsiella pneumoniae was the commonest (20.2\%) followed by Proteus mirabilis (17.8\%) (Additional file 1: Figure S1).

\section{Susceptibility pattern of bacterial isolates}

Klebsiella pneumoniae was highly susceptible to Gentamicin (80.8\%) and moderately susceptible to Ceftriaxone (73.1\%) and Ciprofloxacin (61.5\%), whereas none among these two isolates were susceptible to Ampicillin and Amoxicillin/clavulanic acid. (Additional file 1: Table S1).

\section{Discussion}

CSOM is one of the most important public health concerns particularly in developing countries [1]. Early identification and proper management of these cases is of vital importance particularly in alleviating complications associated with this disease. In the present study, the proportion of patients with chronic suppurative otitis media was found to be $1.4 \%$. This observation was slightly lower than the previous hospital based study in Tanzania [17] and other community based studies conducted in Dar es Salaam and Northern Tanzania [18, 19]. Elsewhere hospital based studies in Sudan [20] and community based studies in India [21] and Solomon Islands [22] had reported higher prevalence than what has been found in our study. This could be attributed to differences in sample size and sampling techniques. Similar to other studies [1], subjects aged below 5 years of age in this study had high proportion of the disease accounting for $26.6 \%$ of all cases of chronic suppurative otitis media. This may be explained by their relative immature immunity, leading to recurrent upper respiratory tract infections and their relatively short and horizontal eustachian tube making them prone to infection. Another key similarity to other studies is that, this study found males to be more affected by CSOM compared to females with male to female ratio of 1.2:1 and this was statistically significant. Such finding shows resemblance to other studies done elsewhere [22] though differing with observed findings done elsewhere with female propensity [23] and equal gender predominance [10]. Since this study employed random selection of subjects, a male predominance might be an incidental 


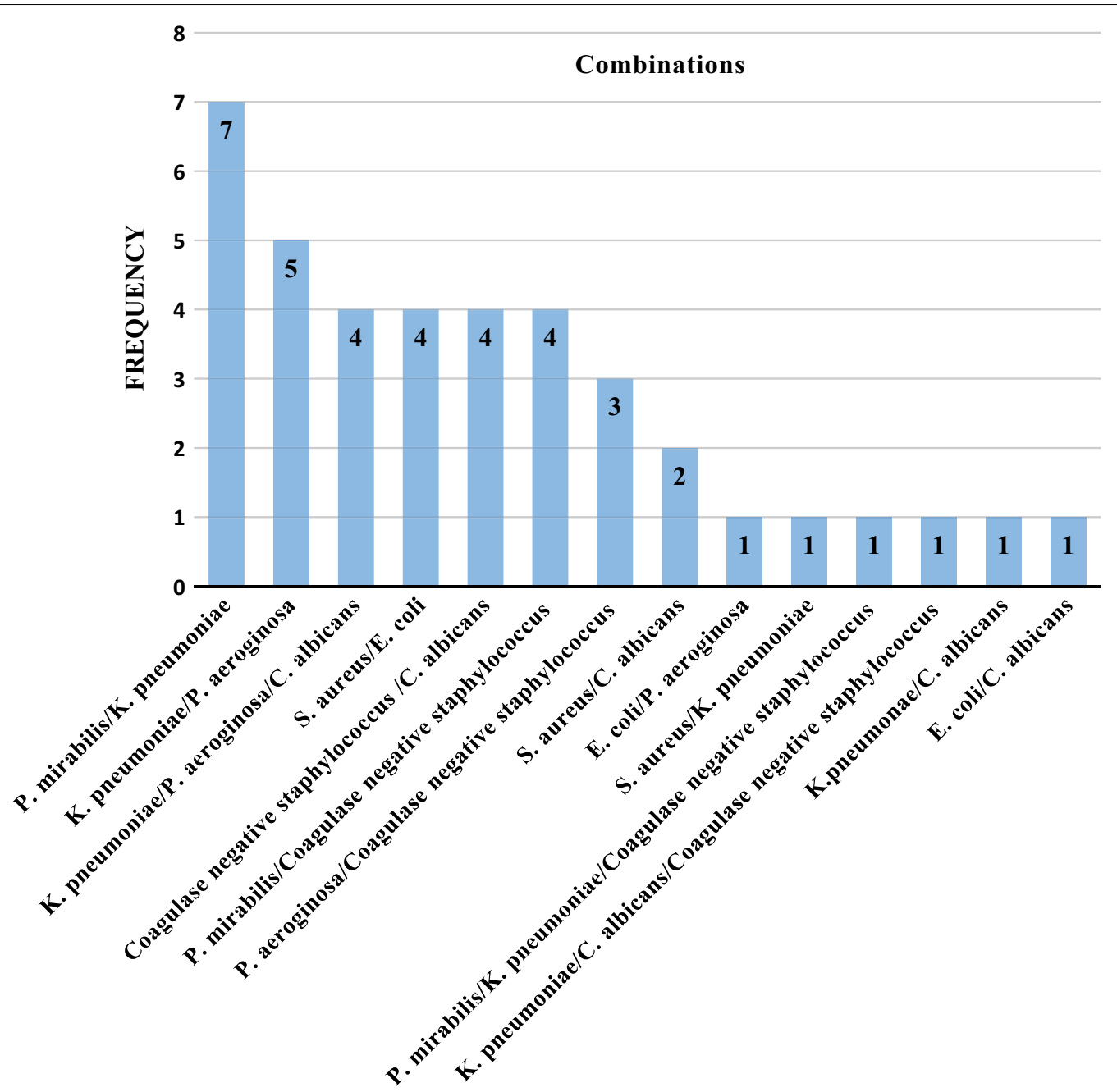

Fig. 1 Polymicrobial combination of isolates

findings and still no known anatomical and genetic differences between male and females pertaining the ear exists.

This study found left ear disease to account for the majority of the cases (58.2\%) with bilateral involvement accounting for the least (2.5\%) number of cases which is similar to what was found by Olowookere et al. [23] though differing with findings established by Taipale et al. and an Aboriginal study [3, 24] with bilateral predominance. Predominance of the left ear may be due to random selection of the study cases but no genetic or structural differences have been identified between the right and left ear.

This study found central perforation (tubotympanic type) to be predominant (53\%) while none of patients had attic perforation. Such findings correlate closely with what was found elsewhere [22, 25].

An analysis of 81 ear pus swabs for culture revealed microbial growth in $98.8 \%$ while the rest had no growth, mixed infections (polymicrobial) accounted for majority of the cases. The commonest mixed infections were of Proteus mirabilis and Klebsiella pneumoniae, followed by Klebsiella pneumoniae and Pseudomonas aeruginosa. Predominance of mixed bacterial infection is in line to previous finding by Gupta et al. [26] from India which found that about $70 \%$ of the CSOM had polymicrobial infections. The polymicrobial nature of the disease may well be explained by the fact that the perforated ear drum makes easier for coliform bacteria such as Escherichia coli and Pseudomonas aeruginosa which are associated with wet and poor hygienic environments and fungi from the external ear to migrate into the middle ear and proliferate.

This polymicrobial nature of the disease with both gram positives, gram negative and fungi necessitates the need for cover with antibacterial drugs with action 
against both gram positive and gram negative with an addition of antifungal drug.

This study also observed that gram negative bacteria accounted for the majority of the isolates while fungi accounted for the least. Most of the isolates were facultative anaerobes similar to what has been reported in other studies $[17,27]$ with other researchers observing gram positive Staphylococcus aureus as the predominant isolates $[28,29]$.

Isolation of coliform bacteria Escherichia coli and Klebsiella pneumoniae which are known to be fecal bacteria and Pseudomonas aeruginosa which is associated with wet environmental conditions suggests people are at high-risk of infection due to poor hygienic environment. These findings were in line with observational study done in Nigeria by Bakari et al. [27] which had Klebsiella pneumoniae as the commonest isolated bacteria. But most authors elsewhere have reported Pseudomonas aeruginosa as the commonest isolates $[17,20,26,30,31]$ while Ferede et al. [32] in their study found Proteus species followed by Staphylococcus aureus as their commonest isolates.

Antimicrobial susceptibility test was carried out for all the aerobic isolates (except for Coagulase negative staphylococcus). Ciprofloxacin was found to be the most effective drug as it has been reported in other studies [27, 33]. This study has thus elucidated the prevalence and etiological profile for CSOM at $\mathrm{MNH}$ which is the largest country's tertiary hospital.

\section{Conclusions}

The prevalence of CSOM at MNH appears to be in line with what has been reported in other parts of the world. A male predominance was found and the left ear was more commonly affected than the right ear. Prevalent polymicrobial nature and antimicrobial resistance among isolates in CSOM cases warrants the need for culture and sensitivity of pus isolates. Ciprofloxacin, Gentamicin, Ceftriaxone and Amikacin are highly recommended as the first line management in patients with CSOM, with consideration of appropriate antifungals for possible fungal etiology as per our study findings.

\section{Limitations}

Due to lack of anaerobic culture facility we couldn't further explore the role of anaerobic bacteria in chronic suppurative otitis media. Contaminants were also identified and this is explained by the nature of swab which was employed.

\section{Additional file}

Additional file 1: Figure S1. Distribution of microbial isolates. Table S1. Susceptibility pattern of bacteria isolated from CSOM.

\section{Abbreviations}

ATCC: American Type Culture Collection; CLSI: Clinical and Laboratory Standards Institute; CSOM: chronic suppurative otitis media; MNH: Muhimbili National Hospital; MRSA: methicillin-resistant Staphylococcus aureus; MSSA: methicillin-susceptible Staphylococcus aureus; ORL: otorhinolaryngology; SD: standard deviation; SIM: sulphur indole and motility; TSI: triple sugar iron; UK: United Kingdom.

\section{Acknowledgements}

We are grateful to all the study participants who without them this research would have not come into accomplishment. Special appreciation goes to $\mathrm{MNH}$ for provision of a conducive environment for conducting our study. Dr. Siwillis Mithe (Clinical Oncologist, Kenya) is acknowledged for proof reading the grammar.

\section{Authors' contributions}

ZSA, DN, AAK, KBM, ERM, EJN and AK participated in the conception and designing of the study. AK and ZSA participated in undertaking the experiments and acquisition of data. ZSA, DN, AAK, KBM, ERM, EJN and AK analyzed and interpreted data. ZSA, DN, AAK, KBM, ERM, EJN and AK participated in manuscript drafting. All authors read and approved the final manuscript.

\section{Funding}

None.

\section{Availability of data and materials}

All relevant data pertinent to this research can be obtained from the corresponding author upon a reasonable request.

\section{Ethics approval and consent to participate}

Ethical clearance was obtained from the Senate Research and Publications Committee of Muhimbili University of Health and Allied Sciences. Permission to conduct the study was obtained from MNH authority as per hospital management protocols. A written informed consent was obtained from participants before recruiting them into our study.

\section{Consent for publication}

Not applicable.

\section{Competing interests}

The authors declare that they have no competing interests.

\section{Author details}

1 Department of Surgery, University of Dodoma, College of Health and Allied Sciences, Box 259, Dodoma, Tanzania. ${ }^{2}$ Department of Otorhinolaryngology, Muhimbili University of Health and Allied Sciences, Box 65001, Dar es Salaam, Tanzania. ${ }^{3}$ Department of Microbiology and Immunology, University of Dodoma, College of Health and Allied Sciences, Box 259, Dodoma, Tanzania.

Received: 12 June 2019 Accepted: 15 July 2019

Published online: 17 July 2019

\section{References}

1. WHO. Child and adolescent health and development. Prevention of blindness and deafness. Chronic suppurative otitis media. Burden of illness and management options. Geneva: WHO; 2004.

2. Adoga A, Nimkur T, Silas O. Chronic suppurative otitis media: socio-economic implications in a tertiary hospital in Northern Nigeria. Pan Afr Med J. 2010;4(1):3.

3. Taipale A, Pelkonen T, Taipale M, et al. Chronic suppurative otitis media in children of Luanda, Angola. Acta Paediatr. 2011;100:84. 
4. Azevedo AF, Pinto DC, Souza NJ, Greco DB, Gonçalves DU. Sensorineural hearing loss in chronic suppurative otitis media with and without cholesteatoma. Revista Brasileira de Otorrinolaringologia. 2007;73(5):671-4.

5. Homøe P, Bjarnsholt T, Wessman M, Sørensen HC, Johansen HK. Morphological evidence of biofilm formation in Greenlanders with chronic suppurative otitis media. Eur Arch Otorhinolaryngol. 2009;266(10):1533-8.

6. Lasisi AO, Sulaiman OA, Afolabi OA. Socio-economic status and hearing loss in chronic suppurative otitis media in Nigeria. Ann Trop Paediatr. 2007;27(4):291-6.

7. Maharjan M, Kafle P, Bista M, Shrestha S, Toran KC. Observation of hearing loss in patients with chronic suppurative otitis media tubotympanic type. Kathmandu Univ Med J. 2009;7(4):397-401.

8. Couzos S, Lea T, Culbong M, Mueller R, Murray R. Effectiveness of ototopical antibiotics for chronic suppurative otitis media in Aboriginal children: a community-based, multicentre, double-blind randomised controlled trial. Med J Aust. 2003;179(4):185-90.

9. Olatoke F, Ologe FE, Nwawolo CC, Saka MJ. The prevalence of hearing loss among schoolchildren with chronic suppurative otitis media in Nigeria, and its effect on academic performance. ENT Ear Nose Throat J. 2008.

10. Matanda RN, Muyunga KC, Sabue MJ, Creten W, de Heyning Van P. Chronic suppurative otitis media and related complications at the University Clinic of Kinshasa. B-ent. 2005;1(2):57-62.

11. Papastavros T, Varlejides S. Reversible and permanent bone conduction threshold shift in cases of chronic suppurative otitis media. Am J Otol. 1986;7(5):338-46.

12. Kaplan DM, Fliss DM, Kraus M, Dagan R, Leiberman A. Audiometric findings in children with chronic suppurative otitis media without cholesteatoma. Int J Pediatr Otorhinolaryngol. 1996;35(2):89-96.

13. Choi HG, Park KH, Park SN, Jun BC, Lee DH, Yeo SW. The appropriate medical management of methicillin-resistant Staphylococcus aureus in chronic suppurative otitis media. Acta Otolaryngol. 2010;130(1):42-6.

14. Park MK, Jung MH, Kang HJ, Woo JS, Lee HM, Jung HH, Hwang SJ, Chae SW. The changes of MRSA infections in chronic suppurative otitis media. Otolaryngol Head Neck Surg. 2008;139(3):395-8.

15. Tiedt NJ, Butler IR, Hallbauer UM, Atkins MD, Elliott E, Pieters M, Joubert G, Seedat RY. Paediatric chronic suppurative otitis media in the Free State Province: clinical and audiological features. S Afr Med J. 2013;103(7):467-70.

16. Bauer AW, Kirby WM, Sherris JC, Turck M. Antibiotic susceptibility testing by a standardized single disk method. Am J Clin Pathol. 1966;45(4_ts):493-6.

17. Moshi NH, Minja BM, Ole-Lengine L, Mwakagile DS. Bacteriology of chronic otitis media in Dar es Salaam, Tanzania. East Afr Med J. 2000;77(1):20-2.

18. Bastos I, Mallya J, Ingvarsson L, Reimer $\AA$, Andréasson L. Middle ear disease and hearing impairment in northern Tanzania A prevalence study of schoolchildren in the Moshi and Monduli districts. Int J Pediatr Otorhinolaryngol. 1995;32(1):1-2.

19. Minja BM, Machemba A. Prevalence of otitis media, hearing impairment and cerumen impaction among school children in rural and urban Dar es Salaam, Tanzania. Int J Pediatr Otorhinolaryngol. 1996;37(1):29-34.
20. Yagi HI. Chronic suppurative otitis media in Sudanese patients. East Afr Med J. 1990;67(1):4-8.

21. Rupa V, Jacob A, Joseph A. Chronic suppurative otitis media: prevalence and practices among rural South Indian children. Int J Pediatr Otorhinolaryngol. 1999;48(3):217-21.

22. Eason RJ, Harding E, Nicholson R, Nicholson D, Pada J, Gathercole J. Chronic suppurative otitis media in the Solomon Islands: a prospective, microbiological, audiometric and therapeutic survey. N Z Med J. 1986:99(812):812-5.

23. Olowookere SA, Ibekwe TS, Adeosun AA. Patterns of tympanic membrane perforation in Ibadan: a retrospective study. Ann Ib Postgrad Med. 2008;6(2):31-3.

24. Morris PS, Leach AJ, Silberberg P, Mellon G, Wilson C, Hamilton E, Beissbarth J. Otitis media in young Aboriginal children from remote communities in Northern and Central Australia: a cross-sectional survey. BMC Pediatr. 2005;5(1):27.

25. Adhikari P. Chronic suppurative otitis media in school children of Kathmandu valley. Int Arch Otorhinolaryngol. 2007;11(2):1-5.

26. Saini S, Gupta N, Sachdeva OP. Bacteriological study of paediatric and adult chronic suppurative otitis media. Indian J Pathol Microbiol. 2005;48(3):413-6

27. Bakari AA, Adoga AA, Afolabi OA, Kodiya AM, Ahmad BM. Pattern of chronic suppurative otitis media at the National Ear Care Centre Kaduna, Nigeria. J Med Trop. 2010. https://doi.org/10.4314/jmt.v12i1.69307.

28. Prakash R, Juyal D, Negi V, Pal S, Adekhandi S, Sharma M, Sharma N. Microbiology of chronic suppurative otitis media in a tertiary care setup of Uttarakhand state, India. N Am J Med Sci. 2013:5(4):282.

29. Pajor A, Durko M, Jankowski A, Bartoszko-Tyczkowska A, Stańczyk R. Bacteriological evaluation in chronic otitis media. Otolaryngol Pol. 2006;60(5):757-63.

30. Sattar A, Alamgir A, Hussain Z, Sarfraz S, Nasir J. Bacterial spectrum and their sensitivity pattern in patients of chronic suppurative otitis media. J Coll Physicians Surg Pak. 2012;22(2):128-9.

31. Gül HC, Kurnaz A, Turhan V, Oncül O, Pahsa A. Microorganisms isolated from middle ear cultures and their antibacterial susceptibility in patients with chronic suppurative otitis media. Kulak burun bogaz ihtisas dergisi KBB. 2006;16(4):164-8.

32. Ferede D, Geyid A, Lulseged S, Melaku A. Drug susceptibility pattern of bacterial isolates from children with chronic suppurative otitis media. Ethiop J Health Dev. 2001;15(2):89-96. https://doi.org/10.4314/ejhd.v15i2 9882.

33. Aduda DS, Macharia IM, Mugwe $P$, Oburra $H$, Farragher B, Brabin B, Mackenzie I. Bacteriology of chronic suppurative otitis media (CSOM) in children in Garissa district, Kenya: a point prevalence study. Int J Pediatr Otorhinolaryngol. 2013;77(7):1107-11.

\section{Publisher's Note}

Springer Nature remains neutral with regard to jurisdictional claims in published maps and institutional affiliations.
Ready to submit your research? Choose BMC and benefit from:

- fast, convenient online submission

- thorough peer review by experienced researchers in your field

- rapid publication on acceptance

- support for research data, including large and complex data types

- gold Open Access which fosters wider collaboration and increased citations

- maximum visibility for your research: over 100M website views per year

At BMC, research is always in progress.

Learn more biomedcentral.com/submissions 